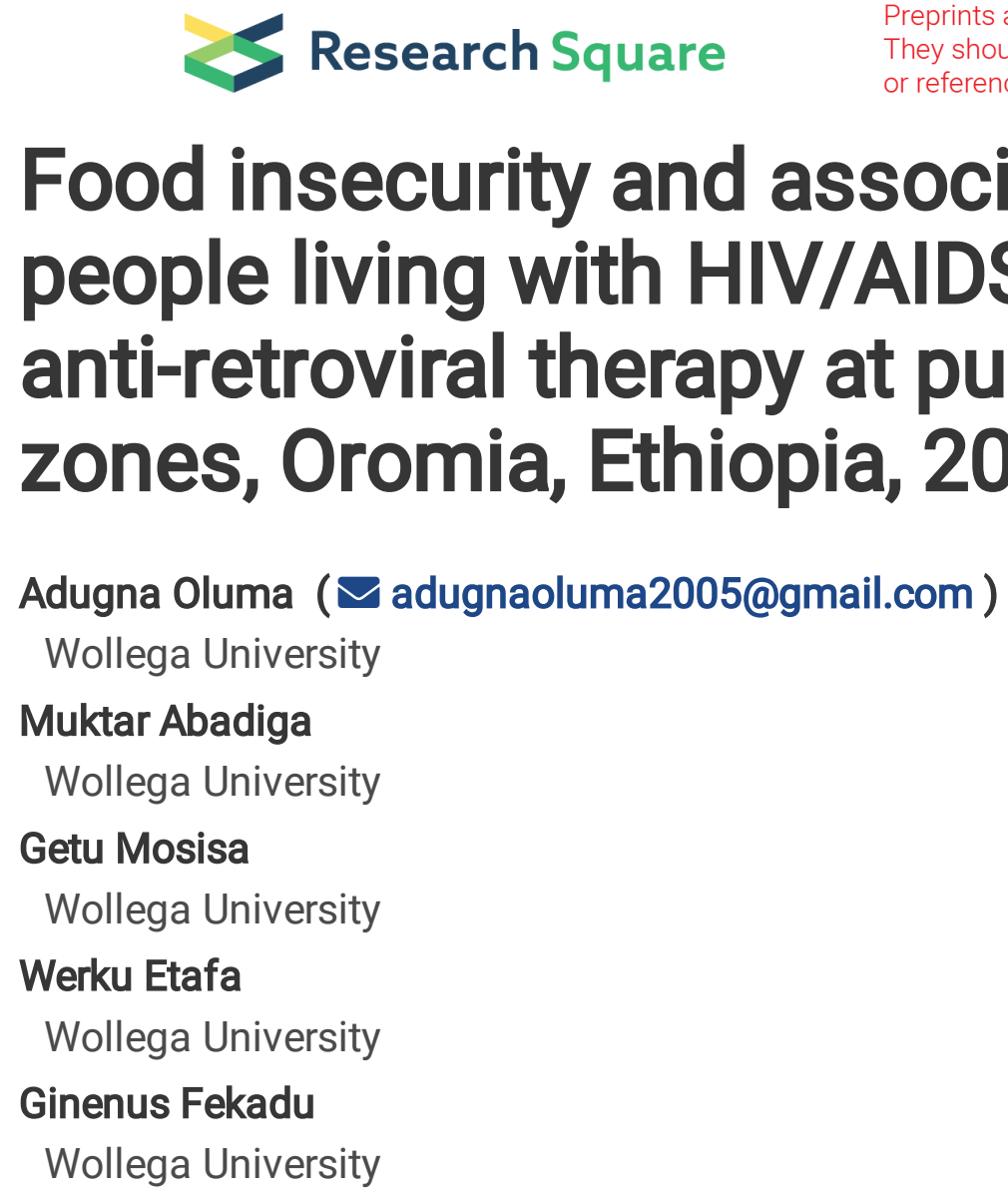

\title{
Food insecurity and associated factors among people living with HIV/AIDS on follow up receiving anti-retroviral therapy at public hospitals of Wollega zones, Oromia, Ethiopia, 2019
}

\section{Research}

Keywords: Food insecurity, HIV/AIDS, PLWHA, Wollega, Ethiopia

Posted Date: December 30th, 2019

DOI: https://doi.org/10.21203/rs.2.19587/v1

License: (c) (i) This work is licensed under a Creative Commons Attribution 4.0 International License. Read Full License 


\section{Abstract}

Background : Food insecurity and HIV/AIDS are intertwined in a vicious cycle through nutritional, mental health, and behavioral pathways. Food insecurity is a potentially important barrier to the success of antiretroviral treatment, increased hospitalizations, and higher morbidity among HIV-infected individuals in resource-poor settings particularly in sub-Saharan Africa including Ethiopia. Therefore, the purpose of this study was to assess the prevalence of food insecurity and its associated factors among adult people living with HIV/AIDS on follow up receiving ART at public hospitals of wollega zone, west Ethiopia.

Methods : An institutional-based cross-sectional study design was conducted on a sample of 428 among people living with HIV/AIDS on follow up receiving anti-retroviral therapy at public hospitals of wollega zones. Data was collected using the Household Food Insecurity Access Scale and dietary diversity scale by interviewer-administered questionnaires. The data was checked, cleaned and entered into Epi data version 3.1 and then exported into Statistical Package for the Social Sciences (SPSS) window version 21 for analysis. Descriptive statistics - cross-tabulation frequency table, mean, standard deviation, percentage, were employed. Bivariate and multiple logistic regression analyses were used with $\mathrm{AOR}$ at $\mathrm{Cl}$ $95 \%$ and $p<0.05$ were used.

Result: The overall prevalence of food insecurity among PLWHA receiving ART therapy was $68.8 \%$ which was partitioned as mild (23.32\%), moderate $(29.09 \%)$ and severe $(16.35 \%)$ food in secured. Being single $[A O R=3.507(1.377,8.934)]$, illiterate $[A O R=5.234(1.747,15.686)]$, cigarette smoking [AOR=3.577(2.104, 6.081)], presence of anemia $(A O R=2.650(1.563,4.493)]$ and inadequate dietary diversity [AOR=2.870(1.088, 7.569)] were predictors of food insecurity.

Conclusion : The prevalence of food insecurity was relatively high. Educational status, marital status, cigarette smoking, presence of anemia, opportunistic infection and inadequate dietary diversity were the major significant factors affecting food insecurity. We recommended Wollega Zonal Health Bureaus to effectively intervene in behavioral modification and health information dissemination (HID) which is the key strategies to improve food security.

\section{Introduction}

Food insecurity is at the heart of the universal movement to overcome hunger and poverty [1]. It refers to the unavailability of adequate and sustainable food supply, inability to access adequate balanced diet, and inability to utilize safe and quality food which is nutritionally adequate and socially acceptable ways for all household members [2].

HIV/AIDS and food insecurity has a bidirectional relationship. Food insecurity increases the risk of HIV infection, as well as HIV infection, leads to food insecurity by reducing agricultural production, reducing income, increasing medical expenses causing reduced capacity to respond to the crisis. Food insecurity affects health directly or indirectly through the impact of poor nutritional status, a social and behavioral mechanism that influences adverse health outcomes $[3,4]$. 
More than 1 billion people worldwide are affected by food insecurity that is inseparably linked to the HIV epidemic in both resource-rich and resource-poor settings. Approximately, $89 \%$ of food-insecure individuals live in Asia and Africa. About 28.5 million HIV/AIDS infected people live in sub-Saharan Africa and about $70 \%$ where food insecurity and malnutrition endemic $[5,6]$.

Worldwide one-third of 40 million PLWHA are co-infected with opportunistic infections related to malnutrition that weakens the immune system, leading to greater susceptibility. About $41 \%$ of adults and $32 \%$ of children had access to antiretroviral treatment [7]. HIV/AIDS and food insecurity are two of the leading causes of morbidity and mortality that increase vulnerability and worsening the severity of one another. The prevalence of food insecurity was high in sub-Saharan Africa among PLWHA particularly in Ethiopia were $63 \%$, Uganda 75\%, Democratic Republic of Congo 57\%, and Tanzania 52\% $[8,9,10,11]$.

Both HIV/AIDS and food insecurity are intertwined in a vicious cycle. HIV/AIDS affects food insecurity mainly through its corrosive effects on people's economic sustainability, through the loss of earnings as a result of disease progression. Food insecurity is recognized as a key determinant of reduced adherence to antiretroviral therapy, increased behavioral risk of HIV transmission, reduced access to HIV treatment, adverse antiretroviral pharmacokinetics, and worse clinical outcomes among HIV infected individuals [12].

The study showed that food insecurity can lead to macronutrient and micronutrient deficiencies, which can affect both vertical and horizontal transmission of HIV through contributing immunologic decline and increased morbidity and mortality. Food insecurity can have mental health consequences, such as depression and increased drug abuse finally contribute to HIV transmission risk and incomplete viral load suppression, increased probability of AIDS-defining illness, and AIDS-related mortality among HIVinfected persons [13].

Study conducted in various countries among PLWHA receiving HAART showed a high prevalence of insecurity indicated that Canada $71 \%$, Namibia92\%, and Kenya revealed that $20-50 \%$ were food insecure $[14,15,16]$.

In Ethiopia, about $1.5 \%$ of adult people aged 15-49 are infected with HIV that was intensely affected by food insecurity. It was estimated that almost 1 in 10 Ethiopians struggled to have access to safe, sufficient and nutritious food for themselves and their families [17].

Study showed that lower age, lower educational level, marital status, low health status, political and demographic factors such as gender, income, body mass index, smoking, household composition, nutritional status, physical and mental development, social vulnerability to infectious and chronic diseases are related to food insecurity[18].

In spite of Food insecurity compromise the effectiveness of HIV treatment, reduce ART adherence, and induce HIV related stigma, isolation and anxiety; understanding the predictors of food insecurity is crucial to create awareness for social support for infected patients and integrates comprehensive nutritional 
therapy for infected individuals. The status of food insecurity is not well known among PLWHA in Wollega zones. Therefore, this study was designed to fill this gap and determine the levels and predictors of food insecurity among adult patients taking highly active anti-retroviral therapy at public hospitals of wollega zones, Oromia, West Ethiopia.

\section{Methods}

Study setting and population

The study was conducted in four Public Hospitals of Wollega Zones (Nekemte referral Hospital (East wollega), Ghimbi hospital (West Wollega), Jimma Arjo Hospital (East wollega) and Nedjo hospital (West Wollega) from September 2019 -October 2019 which were randomly selected. An Institutional based cross-sectional study design was employed. All PLWHA on follow up receiving antiretroviral therapy at the selected hospitals in Wollega zones were source population. A Selected adult PLWHA of above 18 years receiving ART for at least 12 months and present during data collection period were study population. All PLWHA above 18 years and receiving ART more than 12 months were included and those below 18 years and receiving ART less than 12 months and seriously ill and cognitive impaired adult PLWHA was excluded

Sample size determination and sampling techniques

The sample size of the study was calculated using the formula for estimation of a single population proportion with the assumptions of $95 \%$ Confidence Level (CL), marginal error (d) of 0.05 . Taking proportion of $0.63(63 \%)$ from the previous study conducted in Jimma university specialized hospital [8], and by adding a non-response rate of $10 \%$, a total of 428 adult people living with HIV/AIDS on follow up receiving ART were enrolled in the study after using the correction formula. Systematic random sampling method was used to select the study participants.

\section{Data collection tool and procedures}

Data was collected using an interviewer-administered questionnaire. Data collection tools consist of three-parts questionnaires: Demographic related consisting clinical profile, House Hold Food Access Scale (HFIAS) which was taken from tool developed by the Food and Nutrition Technical Assistance (FANTA) project with reliability of Cronbach alpha 0.934[19]. It measures food insecurity in terms of occurrence and frequency questions with a total of 18 items within the previous four weeks. Occurrence questions responded in terms of yes or no options with a score of yes $=1$ or No $=0$. The affirmative responses for occurrence were considered as food insecure scored as rarely (once or twice) $=1$, sometimes (three to ten times) $=2$ and often (more than ten times) $=3$ in the past four weeks. Dietary Diversity Index was taken from UN tool developed by the Food and Agriculture Organization and USAID (FAO) with the reliability of Cronbach alpha 0.637[20].It measure household food insecurity in terms of 7 food items within the previous twenty-four hours by two possible values: $1=y e s$ and $0=$ no. A Close- 
ended interviewer-administered structured questionnaire was distributed to participants by trained data collectors. Data was collected by eight trained Bsc a nurse working in different hospitals.

Data processing and analysis

Data were coded and entered checked, cleaned and entered into Epi Data version 3.1 and then exported to SPSS window version 21 for analysis. Descriptive statistics such as cross-tabulation, frequency, percentages, mean and standard deviation were employed. Binary logistic regression was employed to determine the association between food insecurity and independent variables by using Hosmer and Lemeshow test. Multiple logistic regression analysis was employed by backward stepwise (Wald) model to ascertain predictors of food insecurity among PLWHA receiving ART. Significant variables were determined by AORs, $\mathrm{Cl}$ at $95 \%$ and P-value $<0.05$. Finally, the result was summarized by percent, tables, pie charts, and bar graphs.

Data quality control

All questionnaires were translated into the local language Afan Oromo and then translated back into English languages by experts. Pretest was conducted on $5 \%$ of the questionnaire at Bedelle hospital. Oneday training was also given for data collectors and supervisors. Data were cleaned, coded and checked for consistency and completeness. The principal investigator prepared the template and entered data using Epi Data version 3.1. Finally, after missing, value and incorrect entry checked the data was exported to SPSS version 21.

\section{Results}

Socio-demographic characteristics of respondents

Four hundred sixteen participants were participated giving a response rate of $97.2 \%$. The majority of the respondents $221(53.1 \%)$ were female and with regards to marital status, two thirds $260(62.5 \%)$ were married respondents. The mean age of the respondents was $32.92 \pm 7.304$ years and $197(47.4 \%)$ of the study participants were between 30 to 39 years' age group. Concerning educational status majority, 114 (27.4\%) were can't read and write followed by who can read and write 106(25.5\%). Concerning their occupation, the majority of the respondents $144(34.6 \%)$ were Daily Laborers followed by employee (both governmental and private) $141(33.9 \%)$. The study also showed that majority of respondents $238(57.2 \%)$ gain income less than 600 EBR. Moreover, the study also reveals most of 233(56\%) the respondents' were urban indwellers (Table 1). 
Table 1

Socio-demographic characteristics of respondents among people living with HIV/AIDS on follow up receiving anti-retroviral therapy at public hospitals of Wollega zones, Oromia, Ethiopia, 2019(N = 416)

\begin{tabular}{|c|c|c|c|}
\hline Variable & Category & Frequency (No) & Percent (\%) \\
\hline \multirow[t]{2}{*}{ Sex } & Male & 195 & 46.9 \\
\hline & Female & 221 & 53.1 \\
\hline \multirow[t]{4}{*}{ Age } & $<19$ & 16 & 3.8 \\
\hline & $20-29$ & 115 & 27.6 \\
\hline & $30-39$ & 197 & 47.4 \\
\hline & $>40$ & 88 & 21.2 \\
\hline \multirow[t]{4}{*}{ Marital status } & Married & 260 & 62.5 \\
\hline & Single & 61 & 14.7 \\
\hline & Divorced & 28 & 6.7 \\
\hline & Widowed & 67 & 16.1 \\
\hline \multirow[t]{3}{*}{ Family size } & $<3$ & 236 & 56.7 \\
\hline & $3-5$ & 126 & 30.3 \\
\hline & $>5$ & 54 & 13.0 \\
\hline \multirow[t]{5}{*}{ Educational status } & Can't read and write & 114 & 27.4 \\
\hline & Can read and write & 106 & 25.5 \\
\hline & Completed primary & 81 & 19.5 \\
\hline & Completed secondary & 74 & 17.8 \\
\hline & Completed college and above & 41 & 9.9 \\
\hline \multirow[t]{4}{*}{ Religion } & Orthodox & 203 & 48.8 \\
\hline & Muslim & 38 & 9.1 \\
\hline & Protestant & 163 & 39.2 \\
\hline & Others* & 12 & 2.9 \\
\hline \multirow[t]{2}{*}{ Ethnicity } & Oromo & 333 & 80.0 \\
\hline & Amhara & 66 & 15.9 \\
\hline
\end{tabular}




\begin{tabular}{|c|c|c|c|}
\hline \multirow[t]{3}{*}{ Variable } & Category & Frequency (No) & Percent (\%) \\
\hline & Tigre & 10 & 2.4 \\
\hline & Others** & 7 & 1.7 \\
\hline \multirow[t]{4}{*}{ Occupation } & Farmer & 45 & 10.8 \\
\hline & Merchant & 86 & 20.7 \\
\hline & Employee & 141 & 33.9 \\
\hline & Daily laborer & 144 & 34.6 \\
\hline \multirow[t]{4}{*}{ Languages } & Afan Oromo & 268 & 64.4 \\
\hline & Amharic & 136 & 32.7 \\
\hline & Tigrigna & 7 & 1.7 \\
\hline & 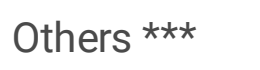 & 5 & 1.2 \\
\hline \multirow[t]{2}{*}{ Residence } & Urban & 233 & 56.00 \\
\hline & Rural & 183 & 44.00 \\
\hline \multirow[t]{3}{*}{ Climatic condition } & Dega & 83 & 20.0 \\
\hline & Weyinadega & 308 & 74.0 \\
\hline & Desert & 25 & 6.0 \\
\hline \multirow[t]{2}{*}{ Farm land } & Yes & yes & 156 \\
\hline & No & no & 260 \\
\hline \multirow[t]{2}{*}{ Irrigation } & Yes & yes & 88 \\
\hline & No & No & 328 \\
\hline \multirow[t]{2}{*}{ Fertilizer } & Yes & Yes & 134 \\
\hline & No & No & 282 \\
\hline \multirow{5}{*}{$\begin{array}{l}\text { Monthly income } \\
\text { in ETB }\end{array}$} & 600 & 238 & 57.2 \\
\hline & $601-1650$ & 71 & 17.1 \\
\hline & $1651-3200$ & 53 & 12.7 \\
\hline & $3201-5250$ & 43 & 10.3 \\
\hline & $5251-7800$ & 11 & 2.6 \\
\hline
\end{tabular}


Clinical profiles, nutritional and art status among the respondents

More than half 245 (58.9\%) of the study participants were at clinical WHO stage I and nearly quarter 102 (24.5\%) were at clinical WHO stage III. The mean and standard deviation of the body mass index of the respondents was $18.60 \pm 3.612$. About one third $136(32.7 \%)$ of the study participants had CD4 count between 351-500cells/ul. The study also reveals that the majority of the respondents had a history of coinfections predominantly Pneumocystis Carini pneumonia and diarrhea (15.4\% and $9.4 \%)$, respectively. With regards to the ART regimen, nearly half of the respondents had taken 202(48.6\%) TDF + 3TC + EFV therapy during follow up. The majority of the respondents $216(51.9 \%)$ were anemic as well as they were cigarette smoker 254(61.1\%). With regards to nutritional counseling 353(84.9\%) had dietary counseling. Almost all 391(94\%) respondents had inadequate dietary diversity (Table 2). 
Table 2

Clinical profiles, nutritional and ART status among people living with HIV/AIDS on follow up receiving anti-retroviral therapy at public hospitals of wollega zones, oromia, Ethiopia, $2019(\mathrm{~N}=416)$

\begin{tabular}{|c|c|c|c|c|}
\hline Variables & & Category & Frequency $(\mathrm{N})$ & $\begin{array}{l}\text { Percent } \\
\text { (\%) }\end{array}$ \\
\hline \multirow{4}{*}{\multicolumn{2}{|c|}{ WHO clinical stage }} & 1st stage & 245 & 58.9 \\
\hline & & 2nd stage & 58 & 13.9 \\
\hline & & 3rd stage & 102 & 24.5 \\
\hline & & 4th stage & 11 & 2.6 \\
\hline \multirow{4}{*}{\multicolumn{2}{|c|}{ CD4 + T cell count }} & $<200$ cells/ul & 34 & 8.2 \\
\hline & & 200-350cells/ul & 114 & 27.4 \\
\hline & & 351-500cells/ul & 136 & 32.7 \\
\hline & & >500cells/ul & 132 & 31.7 \\
\hline \multirow{4}{*}{\multicolumn{2}{|c|}{ Body mass index }} & $<18$ & 265 & 63.7 \\
\hline & & $18-24$ & 125 & 30.0 \\
\hline & & $25-29$ & 20 & 4.8 \\
\hline & & $>30$ & 6 & 1.4 \\
\hline \multirow{2}{*}{\multicolumn{2}{|c|}{ Anemia status }} & Yes & 216 & 51.9 \\
\hline & & No & 200 & 48.1 \\
\hline \multirow{2}{*}{\multicolumn{2}{|c|}{ Cigarette smoking }} & Yes & 254 & 61.1 \\
\hline & & No & 162 & 38.9 \\
\hline \multirow{6}{*}{$\begin{array}{l}\text { Current/past Ol in the past six } \\
\text { months }\end{array}$} & No & & 253 & 60.8 \\
\hline & Yes & Diarrhea & 39 & 9.4 \\
\hline & & TB & 16 & 3.8 \\
\hline & & Oral Trash & 18 & 4.3 \\
\hline & & Pneumocystic Cari & 64 & 15.4 \\
\hline & & Others* & 26 & 6.3 \\
\hline \multirow{2}{*}{\multicolumn{2}{|c|}{ ART regimens }} & $(\mathrm{d} 4 \mathrm{~T}+3 \mathrm{TC}+\mathrm{NVP})$ & 73 & 17.5 \\
\hline & & $(T D F+3 T C+E F V)$ & 202 & 48.6 \\
\hline
\end{tabular}




\begin{tabular}{|c|c|c|c|}
\hline Variables & Category & Frequency $(\mathrm{N})$ & $\begin{array}{l}\text { Percent } \\
\text { (\%) }\end{array}$ \\
\hline & $(A Z T+3 T C+N V P)$ & 53 & 12.7 \\
\hline & $(T D F+3 T C+N V P)$ & 66 & 15.9 \\
\hline & $(\mathrm{AZT}+3 \mathrm{TC}+\mathrm{EFV})$ & 19 & 4.6 \\
\hline & $(T D F+3 T C+L P V / r)$ & 3 & 0.7 \\
\hline \multirow[t]{2}{*}{ Dietary counseling } & Yes & 353 & 84.9 \\
\hline & No & 63 & 15.1 \\
\hline \multirow[t]{2}{*}{ Household dietary diversity } & $\begin{array}{l}\text { Inadequate dietary } \\
\text { diversity }\end{array}$ & 391 & 94.0 \\
\hline & $\begin{array}{l}\text { Adequate dietary } \\
\text { diversity }\end{array}$ & 25 & 6.0 \\
\hline Others ${ }^{*}=($ skin infection, Asthma $)$ & & & \\
\hline
\end{tabular}

Prevalence of food insecurity among the respondents

The overall prevalence of food insecurity among PLWHA receiving ART at therapy at public hospitals of wollega zones was $68.8 \%$. This prevalence was partitioned as mild $(23.32 \%)$, moderate $(29.09 \%)$ and severe (16.35\%) food in secured. The remaining $31.25 \%$ of the respondents were food secured (Fig. 1).

Bivariate logistic regression analysis of factors associated with food insecurity

In this study, Bivariate logistic regression analysis revealed significantly associated variables with food insecurity at $p<0.05$. Among significant variables were sex, marital status, educational status, occupation, and place of residence, family size, and stage of HIV/AIDS, anemia, farmland, and presence of opportunistic infection, cigarette smoking and dietary diversity were significant variables with food insecurity (Table 3 ). 
Table 3

Bivariate logistic regression analysis of factors associated with food insecurity among people living with HIV/AIDS on follow up receiving antiretroviral therapy at public hospitals of Wollega zones, Oromia, Ethiopia,

$$
2019(\mathrm{~N}=416)
$$

\begin{tabular}{|c|c|c|c|}
\hline \multirow{2}{*}{$\begin{array}{l}\text { Predictors } \\
\text { Sex }\end{array}$} & \multicolumn{2}{|c|}{ Food in security } & \multirow[t]{2}{*}{ COR with $95 \% \mathrm{Cl}$} \\
\hline & Yes & No & \\
\hline Male & 71 & 124 & $1.572(1.036,2.386)$ \\
\hline Female & 59 & 162 & 1 \\
\hline \multicolumn{4}{|l|}{ Marital status } \\
\hline Married & 90 & 170 & $2.426(1.236,4.764)$ \\
\hline Single & 22 & 39 & $2.585(1.145,5.837)$ \\
\hline Divorced & 6 & 22 & $1.250(0.417,3.746)$ \\
\hline Widowed & 12 & 55 & 1 \\
\hline \multicolumn{4}{|l|}{ Educational status } \\
\hline Illiterate & 72 & 42 & $4.200(1.530,11.530)$ \\
\hline Literate & 73 & 33 & $3.255(1.172,9.042)$ \\
\hline Completed primary & 54 & 27 & $3.600(1.268,10.219)$ \\
\hline Completed secondary & 51 & 23 & $3.247(1.128,9.345)$ \\
\hline Completed college/university & 36 & 5 & 1 \\
\hline \multicolumn{4}{|l|}{ Occupation } \\
\hline Farmer & 39 & 6 & 1 \\
\hline Merchant & 60 & 26 & $2.817(1.062,7.467)$ \\
\hline Employee & 97 & 44 & $2.948(1.163,7.476)$ \\
\hline Daily laborer & 90 & 54 & $3.900(1.549,9.819)$ \\
\hline \multicolumn{4}{|l|}{ Place of residence } \\
\hline Urban & 87 & 146 & $1.940(1.259,2.991)$ \\
\hline Rural & 43 & 140 & 1 \\
\hline \multicolumn{4}{|l|}{ Family size } \\
\hline$<3$ & 83 & 153 & $2.387(1.143,4.987)$ \\
\hline
\end{tabular}




\begin{tabular}{|c|c|c|c|}
\hline \multirow{2}{*}{$\begin{array}{l}\text { Predictors } \\
4-5\end{array}$} & \multicolumn{2}{|c|}{ Food in security } & \multirow{2}{*}{$\begin{array}{l}\text { COR with 95\% Cl } \\
1.829(.833,4.016)\end{array}$} \\
\hline & 37 & 89 & \\
\hline$>5$ & 10 & 44 & 1 \\
\hline \multicolumn{4}{|l|}{ HIV/AIDS stage } \\
\hline Stage One & 158 & 87 & 1 \\
\hline Stage Two & 41 & 17 & $.753(0.404,1.404)$ \\
\hline Stage Three & 80 & 22 & $.499(0.291,0.857)$ \\
\hline Stage Four & 7 & 4 & $1.038(0.296,3.644)$ \\
\hline \multicolumn{4}{|l|}{ Farm land } \\
\hline Yes & 39 & 117 & 1 \\
\hline No & 91 & 169 & \\
\hline \multicolumn{4}{|l|}{ ANAEMIA } \\
\hline Yes & 137 & 79 & $1.685(1.105,2.568)$ \\
\hline No & 149 & 51 & 1 \\
\hline \multicolumn{4}{|l|}{ Opportunistic infection } \\
\hline Yes & 136 & 27 & 1 \\
\hline No & 150 & 103 & $0.289(0.178,0.469)$ \\
\hline \multicolumn{4}{|l|}{ Types of opportunistic ds } \\
\hline Diarrhea & 32 & 7 & $5.264(1.540,17.993)$ \\
\hline Pulmonary tuberculosis's & 12 & 4 & $1.677(.392,7.184)$ \\
\hline Oral trash & 13 & 5 & $2.556(.490,13.329)$ \\
\hline Pneumocystic cari pneumonia & 56 & 8 & $2.949(.605,14.383)$ \\
\hline Others & 23 & 3 & 1 \\
\hline \multicolumn{4}{|l|}{ Cigarette smoking } \\
\hline Yes & 154 & 100 & $2.857(1.786,4.570)$ \\
\hline No & 132 & 30 & 1 \\
\hline \multicolumn{4}{|l|}{ Dietary diversity } \\
\hline Adequate & 12 & 13 & 1 \\
\hline Inadequate & 274 & 117 & $2.537(1.124,5.725)$ \\
\hline
\end{tabular}


Variables significantly associated with food insecurity in multivariate analysis include marital status, educational status, presence of opportunistic infection, anemic status, cigarette smoking, and dietary diversity. The result showed that PLWHA receiving ART at therapy who were single 3.507 times (AOR = $3.507,95 \% \mathrm{Cl}: 1.377,8.934)$ more likely to be food insecure as compared widowed. With regards to educational status PLWHA receiving ART at therapies that were illiterate 5.234 times (AOR $=5.234,95 \% \mathrm{Cl}$ : $1.747,15.686)$ more likely to be food insecure as compared those completed college/university. The results also showed that cigarette smokers were 3.577 times $(A O R=3.577,95 \% \mathrm{Cl}=2.104,6.081)$ more likely food insecure compared to non-smokers. Regarding anemia status among PLWHA receiving ART at therapy, anemic patients were 2.650 times $(A O R=2.650,95 \% \mathrm{Cl}=1.563,4.493)$ more likely food insecure compared to patient free of anemia. The result also revealed that PLWHA receiving ART at therapy having inadequate dietary diversity were $2.870(\mathrm{AOR}=2.870,95 \% \mathrm{Cl}=1.088,7.569)$ more likely food insecure compared to patient having adequate dietary diversity (Table 4). 
Table 4

Multivariate logistic regression analysis of factors associated with food insecurity among people living with HIV/AIDS on follow up receiving antiretroviral therapy at public hospitals of Wollega zones, Oromia, Ethiopia,

$$
2019(\mathrm{~N}=416)
$$

\begin{tabular}{|c|c|c|c|}
\hline \multirow{2}{*}{$\begin{array}{l}\text { Predictors } \\
\text { Marital status }\end{array}$} & \multicolumn{2}{|c|}{ Food in security } & \multirow[t]{2}{*}{ AOR with $95 \% \mathrm{Cl}$} \\
\hline & Yes & No & \\
\hline Married & 90 & 170 & $3.133(1.448,6.782)$ * \\
\hline Single & 22 & 39 & $3.507(1.377,8.934)$ * \\
\hline Divorced & 6 & 22 & $1.352(0.406,4.502)$ * \\
\hline Widowed & 12 & 55 & 1 \\
\hline \multicolumn{4}{|l|}{ Educational status } \\
\hline Illiterate & 72 & 42 & $5.234(1.747,15.686)$ * \\
\hline Literate & 73 & 33 & $4.330(1.436,13.053)$ * \\
\hline Completed primary & 54 & 27 & $4.550(1.472,14.070)$ * \\
\hline Completed secondary & 51 & 23 & $3.400(1.102,10.493)$ * \\
\hline Completed college/university & 36 & 5 & 1 \\
\hline \multicolumn{4}{|l|}{ ANAEMIA } \\
\hline Yes & 137 & 79 & $2.650(1.563,4.493)$ * \\
\hline No & 149 & 51 & 1 \\
\hline \multicolumn{4}{|l|}{ Opportunistic infection } \\
\hline Yes & 136 & 27 & 1 \\
\hline No & 150 & 103 & $0.179(0.101,0.316)$ * \\
\hline \multicolumn{4}{|l|}{ Cigarette smoking } \\
\hline Yes & 154 & 100 & $3.577(2.104,6.081)$ * \\
\hline No & 132 & 30 & 1 \\
\hline \multicolumn{4}{|l|}{ Dietary diversity } \\
\hline Adequate & 12 & 13 & 1 \\
\hline Inadequate & 274 & 117 & $2.870(1.088,7.569)$ * \\
\hline
\end{tabular}




\section{Discussion}

The overall prevalence of food insecurity was $68.8 \%$ with the majority were moderately $(29.09 \%)$ followed by mild (23.32\%), and severe (16.35\%) food in secured. This finding was relatively lower than a previous study conducted in Butajira hospital SNNP of Ethiopia which was $78.1 \%$ i.e (mild (4.4\%), moderate $(32.0 \%)$ and severe $(41.7 \%)$ food insecurity of the respondents. The discrepancy of food insecurity might be due to the improvement of socio-economic status, lifestyle modification at the household level and improved agricultural policy endorsed by the government [21].

The study revealed that educational status was the strongest factor independently associated with food insecurity considering the joint effect of other variables in the regression model. Being illiterate was increased the odds of food insecurity by five $(A O R=5.234,95 \% \mathrm{Cl}: 1.747-15.686)$ times compared with completed college/university. These findings were similar to a study conducted in Dilla University Referral Hospital that revealed respondents who not able to read \& write were four ( $\mathrm{AOR}=3.5,95 \% \mathrm{Cl}: 1.35-8.02)$ times increased odds of malnutrition compared with completed grade $1-4$ [22].

In a similar way study conducted in Portugal indicated having no education was eight ( $A O R=7.98$, $95 \% \mathrm{Cl}: 4.73,13.49)$ times increased odds of food insecurity compared with completed greater than 10 th grades. This similarity justifies that the consequences due to lack of education increase food insecurity in the global context. The study also indicated that cigarette smoking was a factor independently associated with food insecurity considering the joint effect of other variables in the regression model. Cigarette smokers was increased the odds of food insecurity by four (AOR $=3.577,95 \% \mathrm{Cl}: 2.104,6.081$ ) times compared with non-smokers. This findings was similar to a study conducted in the Portuguese population that revealed respondents who were cigarette smoker two $(A O R=1.56,95 \% \mathrm{Cl}$ : $11.20,2.02$.) times increased odds of food insecurity compared with non-smokers [23].

Also, the study showed that respondents who developed opportunistic infection was $18 \%$ less likely increased the odds of food insecurity (AOR $=0.179,95 \% \mathrm{Cl}: 0.101,0.316)$ compared with patient without opportunistic infection. This finding was contrary to a study conducted in Arba Minch General Hospital SSNP Ethiopia (AOR $=8.03,95 \% \mathrm{Cl}: 3.84,16.78)$ [24].

The study showed that the WHO clinical stages of HIV/AIDS stages IV and II were significantly associated with food insecurity which was supported by a study conducted in West Shewa revealed WHO clinical stages III and IV[25].

The other relevant predictor was dietary diversity strongly associated with food insecurity. Participants who had inadequate dietary diversity were three times (AOR $=2.870,95 \% \mathrm{Cl}: 1.088,7.569)$ more likely food in secured compared to those had adequate dietary diversity. This study was similar with conducted in Butajira hospital SSNP of Ethiopia that revealed inadequate dietary diversity were fourteen times (AOR = $14.1,95 \% \mathrm{Cl}$ : 4.81-41.3) more likely food in secured compared with adequate dietary diversity. This similarity justify that the habitual dietary pattern across the country among different ethnic groups were similar [21]. 
Causality cannot be confirmed since the research design is cross-sectional.

\section{Conclusion}

The proportion of food insecurity among PLWHA on follow up receiving ART was found relatively high. This study found that educational status, marital status, cigarette smoking, presence of anemia, and inadequate dietary diversity were positively related to food insecurity. Enhancing educational status and behavioral modification is essential to improve food security. It is also better to provide health information dissemination (HIS) on a strategy to prevent the development of co-infections with HIV/AIDS by incorporating various nutrition's in households' usage.

\section{Abbreviations}

AIDS: Acquired Immunodeficiency syndrome, ART: Anti-Retroviral Therapy, BSC: Bachelor Science, FAO: Food and Agricultural Organization, FANTA:Food and Nutrition Technical Assistance, FFQs: Food Frequency Questionnaires, HAART: Highly Active Anti-Retroviral Therapy, HFIAS: Household Food Insecurity Access Scale, HID: Health Information Dissemination, HIV: Human Immuno Virus, OSSA: Organization for Social Service Association, PLWHA: People Living with HIV AIDS, SSA: Sub Saharan Africa, WHO: World Health Organization

\section{Declarations}

\section{Ethical approval and consent to participate}

The study was reviewed and approved by the Institutional Review Boards of Wollega university Ethical review board. The purpose of the study was explained to the medical director and staff of the hospital and permission was obtained. All participants of the study were provided written consent, clearly stating the objectives of the study and their right to refuse. No minors were involved in the study and the consent was obtained from the participants themselves. Moreover, the confidentiality of the information was assured.

\section{Consent for publication}

Not applicable

\section{Availability of data and materials}


The data used during this study are available from the corresponding author on reasonable request.

\section{Competing Interests}

We declare that we have no competing interests.

\section{Funding}

This research work was funded by Wollega University. The funder didn't participate in designing and data collection, analysis, writing, and submission of the article for publication

\section{Authors' Contributions}

The study was conceptualized, result writing, analyses, and the manuscript was written by AO. Other authors MA, GM, WE and GF were involved in reviewing and approving the final manuscript.

\section{Acknowledgment}

We would like to acknowledge Wollega University for financial support. We also would like to acknowledge Wollega public hospitals. We are also grateful to the study participants who voluntarily agreed to be interviewed and participated in the study.

\section{References}

1. Pasquale De Muro and Francesco Burchi. Education for Rural People and Food Security. A Cross Country Analysis. Food and agriculture organization of the United Nations Rome, the ERP publications. 2007:8-14

2. "Food Security Concepts and Frameworks" available at: foodsec.org/dl

3. Weiser SD, Young SL, Cohen CR, Kushel MB, Tsai AC. Conceptual framework for understanding the bidirectional links between food insecurity and HIV/AIDS. Am J Clin Nutr. 2011:1729-1739

4. Sheri D.Weiser, MD, MPH. Current Knowledge, Gaps, and Research Priorities. Food Insecurity and HIV/AIDS. Current Medicine Group LLC. 2009;6(1):225-227

5. United Nations Programme on HIV and AIDS. World AIDS Campaign 2004: women, girls, HIV and AIDS, 2007

6. Sheri D Weiser, Sera L Young, Craig R Cohen, Margot B Kushel. United Nations Food and Agriculture Organization. The State of Food Insecurity in the World: High Prices and Food Security. Threats and Opportunities. Am J Clin Nutr.2008

7. Marti J van Liere. HIV/AIDS and Food Security in Sub-Saharan Africa. Royal Tropical Institute, the Netherlands. International Service for National Agricultural Research.2002

8. Tiyou A, Belachew T, Alemseged $F$ and Biadgilign S. Food insecurity and associated factors among HIV-infected individuals receiving highly active antiretroviral therapy in Jimma zone Southwest 
Ethiopia. Nutrition Journal 2012 11:51.

9. Alexander C Tsai, David R. Bangs berg, Nneka Emenyonu,Senkungu,Jeffrey N. Martin and Sheri D. Weiser.The social context of food insecurity among persons living with HIV/AIDS in rural Uganda. Soc Sci Med. 2011; 73(12): 1717-1724

10. Belachew T, Alemseged. 2012; Musumari PM, Wouters E, Kayembe PK, Kiumbu Nzita M, Mbikayi SM, Democratic Republic of Congo;2014

11. Mshana GH, Wamoyi J, Busza J.Barrier to accessing antiretroviral therapy in Kisesa, Tanzania. Qualitative study of early rural referral to the national program. AIDS patient care STDS.2006; 20(1):649-657

12. Joint United Nations Programme on HIV/AIDS (UNAIDS): Available at http://www.unaids.org/en/KnowledgeCentre/HIVData/Global-Report/2008/. Accessed September 29, 2008.

13. Seager Ganyaza-Twalo T, Tamasane T. Development of conceptual framework to understand the interactions between poverty and HIV/AIDS at the household level of Cape Town, South Africa: Human Sciences Research Council.2007

14. Anema A, Druyts E, Weiser SD, Fernandes KA, Brandson EK, et al. Prevalence and correlates of food insecurity in a Canadian cohort of HIV-infected individuals receiving highly active antiretroviral therapy. 2014

15. Steven Y, Theresa J. FANELLI, MD. Household Food Insecurity Associated with Antiretroviral Therapy Adherence Among HIV-infected Patients. J Acquir Immune Defic Syndr. 2014 ; 67(4):1-7

16. Sheri D Weiser, Sera L Young, Craig R Cohen, Margot B Kushel, Alexander C Tsai, Phyllis C Tien, Abigail M Hatcher, Edward A Frongillo, and David R Bangs berg .Conceptual framework for understanding the bidirectional links between food insecurity and HIV/AIDS. Am J Clin Nutr, 2011; 94(1):1729-1739

17. Kirsty Lewis. Understanding climate as a driver of food insecurity in Ethiopia,2017

18. Laraia BA, Siega-RizAM, and Evenson KR.self-reported overweight and obesity are not associated with concern about enough food among adult in New York and Louisiana. Preventive medicine.2004; 38(1):175-181

19. Coates et al, (2007). "Household Food Insecurity Access Scale (HFIAS) for Measurement of Food Access: Indicator Guide. Version 3"

20. Food and Agriculture Organization, 2010. Guideline for measuring household and individual dietary diversity.

21. Gedle D, Mekuria G, Kumera G, Eshete T, Feyera F. Food Insecurity and its Associated Factors among People Living with HIV/AIDS Receiving Anti-Retroviral Therapy at Butajira Hospital, Southern Ethiopia. J Nutr Food Sci. 2015; 5(1): 1-6

22. Hailemariam et al.: Malnutrition: Prevalence and its associated factors in People living with HIV/AIDS, in Dilla University Referral Hospital. Archives of Public Health,2013;71:3-9 
23. Álvares $L$ and Teresa F.Food insecurity and associated factors in the Portuguese population. Food and Nutrition Bulletin, 2014;35(4 ):1-4

24. Belijo ZN, Mensa M. Levels and Predictors of Food Insecurity among HIV Positive Adult Patients Taking Highly Active Antiretroviral Therapy at Arba Minch General Hospital, Southern Ethiopia, Gen Med (Los Angeles),2016; 5(1)

25. Yilma D, TesfamariamK, Mulu E, and Tezera R. Food Insecurity, Nutritional Status, and Factors Associated with Malnutrition among People Living with HIV/AIDS Attending Antiretroviral Therapy at Public Health Facilities in West Shewa Zone, Central Ethiopia. Hindawi BioMed Research International,2018; https://doi.org/10.1155/2018/1913534

\section{Figures}

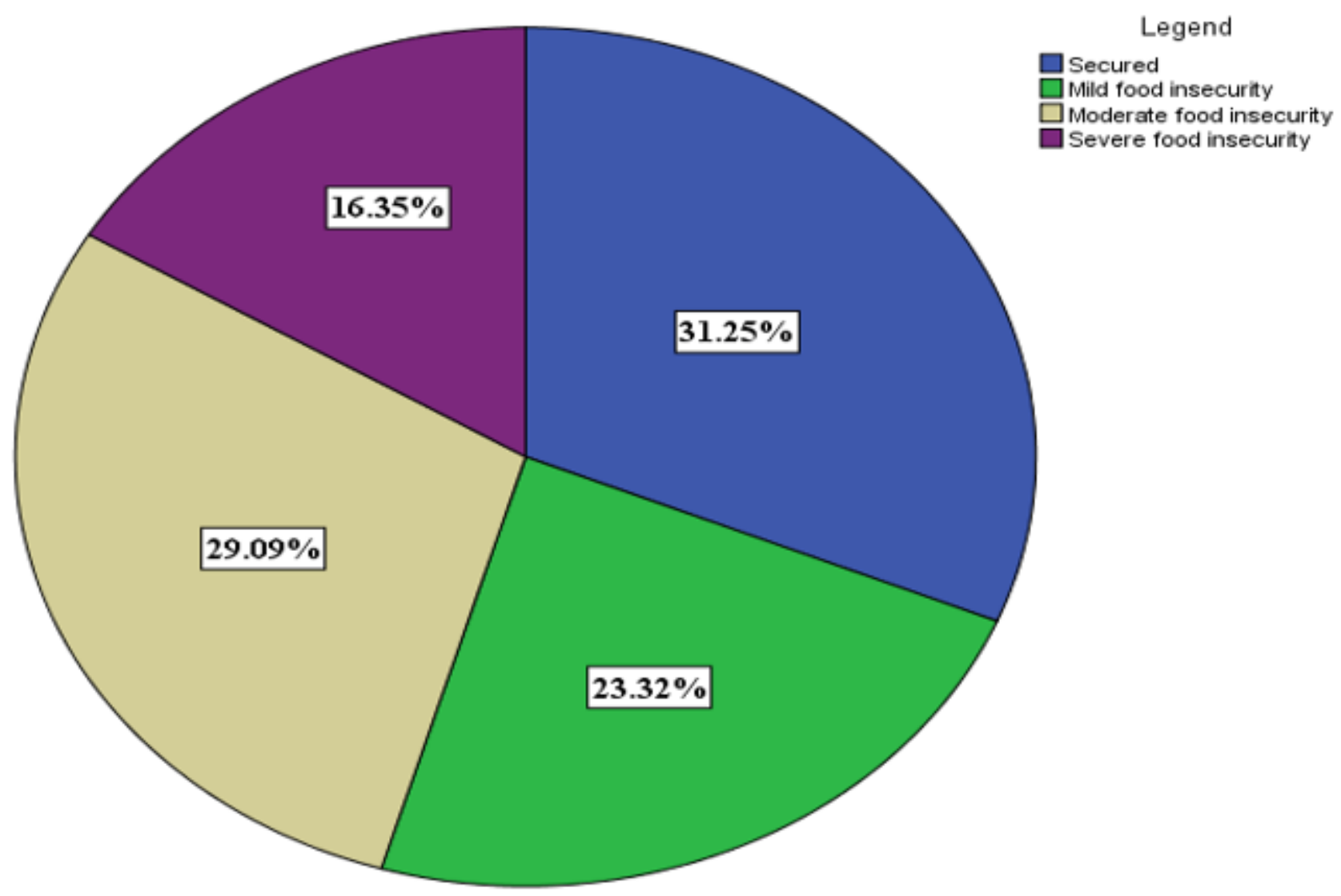

\section{Figure 1}

Pie chart Illustrating Prevalence of food insecurity among the respondents among people living with HIV/AIDS on follow up receiving anti-retroviral therapy at public hospitals of Wollega zones, Oromia, Ethiopia, 2019 